Астахов Юрий Викторович

кандидат социологических наук, доцент, докторант кафедры социальных технологий Института управления

Белгородского государственного национального исследовательского университета

\section{НЕКОТОРЫЕ АСПЕКТЫ УПРАВЛЕНИЯ СИСТЕМОЙ КАДРОВОГО ОБЕСПЕЧЕНИЯ УСТОЙЧИВОГО РАЗВИТИЯ МУНИЦИПАЛЬНОГО ОБРАЗОВАНИЯ}

Аннотация:

В статье проведен анализ функционирования, взаимодействия и взаимовлияния подсистем профессионального образования и рынка труда муниципального образования, которые создают единую систему кадрового обеспечения. При этом обозначенную систему необходимо рассматривать как совокупность подсистем профессионального образования и рынка труда, ориентированную на достижение стратегических целей развития территории муниципального образования путем выработки согласованных действий со всеми ее участниками. Оптимальным, по нашему мнению, яөляется такое состояние систем, которое эффективно обеспечивает потребности муниципалитета в кадрах $u$ направлено на повышение его результативности с учетом ограничений, связанных с демографической ситуацией, санкциями, введенными США и Евросоюзом против России, а также отсутствием бюджетных средств на производство и подготовку кадров по стандартам третьего поколения.

Ключевые слова:

муниципальное образование, кадровое обеспечение устойчивого развития, профессиональное образование, система управления, кадровый потенциал, рынок труда.
Astakhov Yury Viktorivich

PhD in Social Science, Associate Professor Doctoral student, Social Technologies Department, Institute of Management, Belgorod State National Research University

\section{SEVERAL ASPECTS OF STAFFING SYSTEM MANAGEMENT TO ENSURE THE SUSTAINABLE DEVELOPMENT OF THE MUNICIPALITY}

Summary:

The study analyzes the operation, interaction and mutual influence of the subsystems of vocational education and the labor market of the municipality which create a unified staffing system. At the same time, the above-mentioned system is to be reviewed as a set of the subsystems of vocational education and the labor market focused on achieving the strategic objectives of the municipality's development through the concerted actions by all parties to it. In the author's opinion, the system under review is considered to be effective if it can provide the municipality with the staff required and enhance its efficiency in the context of restrictions related to the demographic situation, sanctions imposed by the United States and the European Union against Russia as well as the lack of budgetary funds to train personnel according to the third-generation learning standards.

Keywords: municipality, staffing sustainable development, vocational education, management system, HR capacity, labor market.

Преобразования, происходящие в экономике, политике и социальной сфере новой России в XXI в., определяют необходимость изучения механизма феномена устойчивого развития регионов, муниципальных образований с учетом их территориальных особенностей. Во-первых, в условиях муниципальной реформы, возросшей самостоятельности органов местного самоуправления должны быть четко отработаны вопросы координации деятельности, согласования позиций всех заинтересованных лиц и органов, устранения противоречий и определения адекватных им функций институциональных структур, занимающихся разработкой и реализацией разных составляющих социально-экономической политики регионов, муниципальных образований, в том числе кадровой, инвестиционной, бюджетной, налоговой. Во-вторых, как мы полагаем, одним из важнейших направлений деятельности органов муниципального управления является муниципальная кадровая политика.

В связи с этим следует отметить, что успешность решения вопросов кадрового обеспечения устойчивого развития муниципальных образований находится в прямой зависимости от состояния системы образования, а именно от масштабов, тенденций и уровня подготовки, переподготовки, повышения квалификации и опережающего образования кадров, которые она способна обеспечить. Поэтому правомерно считать, что система образования в современных условиях является эффективным инструментом регулирования в вопросе кадрового обеспечения специалистами органов муниципальной власти, предприятий и организаций независимо от организационно-правовой формы собственности. 
Поскольку профессиональное образование является, с одной стороны, отраслью экономики страны, а с другой - подсистемой, обеспечивающей кадрами все области жизнедеятельности общества, то при стратегическом планировании модернизации образования необходимо ориентироваться на потребности, во-первых, муниципальной и региональной экономики и социальной сферы, во-вторых, органов власти муниципального и регионального управления, в-третьих, рынка труда и общества в целом. В результате такого подхода и учета обозначенных потребностей профессиональное образование становится действенным механизмом формирования кадрового потенциала в органах местного самоуправления.

В связи с этим невозможно не согласиться с мнением председателя Совета Федерации В.И. Матвиенко, которая предлагает разработать концепцию непрерывного образования муниципальных служащих. Подобный шаг мог бы стимулировать дальнейшее развитие кадров местного самоуправления в России [1]. Научную актуальность и практическую значимость данной проблемы усиливает то обстоятельство, что наряду с системой правовых организационных институтов кадровое обеспечение устойчивого развития муниципальных образований в современных условиях второго десятилетия XXI в. является одной из главных ее составляющих.

Функционирование, взаимодействие и взаимовлияние подсистем профессионального образования и рынка труда муниципального образования создают единую систему кадрового обеспечения. Важными в данном аспекте являются вопрос практической деятельности каждого из ее элементов, характер их взаимосвязи, взаимозависимости и общей деятельности. При этом обозначенную систему необходимо рассматривать как совокупность подсистемы профессионального образования и рынка труда, ориентированную на достижение стратегических целей развития территории муниципального образования путем выработки согласованных действий со всеми ее участниками. Оптимальным, на наш взгляд, можно считать такое состояние системы, которое эффективно обеспечивает потребности муниципального образования в кадрах и направлено на повышение его результативности с учетом ограничений, связанных с демографической ситуацией, санкциями, введенными США и Евросоюзом против России, а также отсутствием в муниципалитетах бюджетных средств на производство и подготовку кадров по стандартам третьего поколения. Между тем в новой России в XXI в. делаются только первые шаги в отношении ошибок, допущенных руководством, не ответившим своевременно на актуальные вызовы.

Известно, что в современном мире образование является главным ресурсом и залогом успешного развития общества. Неслучайно в Послании Федеральному собранию президент РФ В.В. Путин главной надеждой России назвал высокий уровень образования населения, прежде всего - нашей молодежи [2]. Чем больше государство, общество и бизнес вкладывают в образование, тем выше потенциал страны, человеческий капитал, а значит, и многообразнее перспективы строительства процветающей новой России.

В связи с этим мы солидарны с мнением профессора А.Л. Сафонова, который полагает, что «требуются разработка и реализация программы государственного инновационного управления развитием образования, направленного на создание опережающего образовательного продукта в виде развитого и актуального человеческого потенциала. Решение этой задачи, несомненно, является одной из ключевых проблем развития образования в целом и "дает ключ" к построению структуры и содержанию образовательных программ будущего, включая образование будущих управленцев государственных и муниципальных служащих» [3].

В данном контексте необходимо отметить, что состояние и перспективы развития экономики знаний рассматриваемой системы в первую очередь определяются аналогичными характеристиками хозяйственной структуры муниципального образования, его особенностями и стратегией устойчивого социально-экономического развития. Управление системой кадрового обеспечения устойчивого развития и ее компонентами служит основополагающей частью системы управления муниципалитетом.

Известно, что универсального алгоритма создания эффрективных систем управления не существует, между тем мы полагаем, что возможна разработка новых инновационных методик и общих принципов их построения. При этом весьма важно сформировать систему научно-методических подходов и дальнейшего совершенствования системы кадрового обеспечения территории в целях повышения эффективности использования ее экономического, и прежде всего кадрового, потенциала за счет подготовленных специалистов.

Наиболее эффективным подходом к управлению, по нашему мнению, является процессный, сущность которого заключается в выделении в объекте управления сети процессов для достижения максимальной эффеективности деятельности системы в целом. В данном случае система кадрового обеспечения устойчивого развития территории муниципального образования представляется динамической системой со своими входами и выходами, обеспечивающими связь с внешней и внутренней средой и управлением внутри себя. 
Контроль, оценка, анализ и мониторинг динамики воспроизводственных процессов в муниципальном образовании, в том числе в рамках системы кадрового обеспечения устойчивого развития, позволяют сорормировать адекватный им механизм управления. В этом контексте представляет интерес мнение М.Г. Некрасовой, что основной функцией системы предлагаемой модели является обеспечение соответствия состояний системы профессионального образования кадров и рынка труда стратегии устойчивого социально-экономического развития муниципального образования. Объект деятельности - социальная (личностно ориентированная) среда, включающая в себя отношения между муниципальным рынком труда, образовательной системой, представительным и исполнительно-распорядительным органами муниципального управления [4].

В такой постановке проблемы содержание концепции кадрового обеспечения устойчивого развития территории муниципального образования определяет следующие компоненты:

- приоритетность направлений реализации принятой стратегии устойчивого развития муниципального образования, муниципальной кадровой политики;

- потребность в трудовых ресурсах с учетом профессионально квалифицированных характеристик кадрового потенциала;

- взаимосвязь и взаимоотношения, возникающие между субъектами системы кадрового обеспечения устойчивого развития территории;

- направления дальнейшего развития образовательной системы как опосредованного инструмента реформирования муниципальной экономики и социальной сферы.

Характерно, что верхний уровень данной модели представляет собой совокупность, или композицию, трех процессов: во-первых, согласование направлений взаимодействия в системе кадрового обеспечения; во-вторых, воспроизводство трудовых ресурсов; в-третьих, финансовое обеспечение деятельности.

На этапе выработки согласованных условий взаимодействия в системе кадрового обеспечения устойчивого развития территории муниципального образования происходит анализ ее внешних и внутренних условий функционирования. Внешним окружением системы являются муниципальные процессы, направленные в целом на дальнейшее социально-экономическое развитие муниципалитета. Поэтому необходимо определить критерии основных социально-экономических факторов и их взаимосвязь, осуществить мониторинг показателей состояния системы кадрового обеспечения. Это позволит, как нам представляется, во-первых, воздействовать на образовательную систему; во-вторых, влиять на состояние муниципального рынка труда и, как результат, обеспечивать регулирование изменений динамики актуализированных социальноэкономических параметров.

Профессиональная подготовка и переподготовка кадров и непосредственное использование трудовых ресурсов происходят в процессе их воспроизводства и востребованности. На этом этапе от высших и средних образовательных учреждений, предприятий и организаций независимо от организационно-правовой формы собственности муниципального образования собирается текущая информация о функционировании компонентов и (или) подсистемы системы кадрового обеспечения территории муниципалитета.

При этом необходимо отметить, что организация данной деятельности должна иметь финансовое обеспечение из бюджетных или внебюджетных источников органов местного самоуправления. В результате такого подхода на муниципальной практике осуществляются стратегическое планирование устойчивого развития, проектное управление, организационные и научнометодические изменения функционирования компонентов и подсистем системы кадрового обеспечения устойчивого развития муниципального образования.

В целях регулярного мониторинга необходимо выделить критерии и (или) наиболее значимые характеризующие их показатели, что позволяет в динамике анализировать и отслеживать ход процесса. Этому в большой мере будет способствовать разработанная нами концепция. Таким образом, предложенная инновационная модель управления системой кадрового обеспечения устойчивого развития территории муниципального образования позволяет осуществлять оперативное управление на уровне отдельных процессов, механизмов и технологий исходя из единой стратегической цели деятельности всей системы.

Новизна представленной модели при внедрении в муниципальную практику заключается в следующем:

- разграничивает ответственность и полномочия должностных лиц, структурных подразделений исполнительного органа муниципальной власти в рамках определенного технологического процесса;

- позволяет топ-менеджерам, руководителям органов местного самоуправления оперативно пользоваться необходимой информацией для принятия кадровых решений на основе мониторинга и полученной достоверной информации. 
Для органов муниципального управления практическая значимость разработанной модели состоит в обеспечении следующих возможностей:

- во-первых, достижения сбалансированного состояния кадровой составляющей муниципального рынка труда;

- во-вторых, количественной и структурной оптимизации системы профессионального образования кадров муниципального образования;

- в-третьих, повышения степени дальнейшей управляемости экономическим и социальным блоками муниципального образования в рамках принятой стратегии устойчивого социальноэкономического развития территорий;

- в-четвертых, в конечном счете увеличения эффрективности работы муниципальных органов власти.

Также необходимо отметить, что предложенная модель может служить отправной точкой для дальнейшей работы по совершенствованию технологического процесса взаимодействия всех заинтересованных сторон в повышении эффективности муниципального управления, воспроизводства трудовых ресурсов и кадрового обеспечения устойчивого развития территории муниципального образования через управление системой образования. Следовательно, реализация на практике данной модели, высокое и эффективное качество муниципального управления, богатая общеобразовательная среда являются ключевыми фракторами для максимального раскрытия кадрового потенциала устойчивого развития муниципальных образований.

\section{Ссылки:}

1. Петров В. Слово за действом // Российская газета. 2014. 22 апр.

2. Послание президента Федеральному собранию [Электронный ресурc]. URL: http://kremlin.ru/events/president/news/56957 (дата обращения: 04.04.2018).

3. Сафонов А.Л. Развитие и управление человеческим потенциалом в системе государственной службы РФ // Человеческий капитал. 2012. № 9. С. 6 ; Buford J.A., Lindner J.R. Human resource management in local government: concepts and applications for HRM students and practitioners. Cincinnati, Ohio, 2002. 485 p. ; Noe R.A. Human resource management: gaining a competitive advantage. N. Y., 2013. $758 \mathrm{p}$.

4. Некрасова М.Г. Моделирование системы управления кадровым обеспечением территории // Инженерное образование. 2007. № 4. С. 215-216.

\section{References:}

Buford, JA \& Lindner, JR 2002, Human resource management in local government: concepts and applications for HRM students and practitioners, Cincinnati, Ohio, $485 \mathrm{p}$.

Nekrasova, MG 2007, 'Modeling of the territory staffing management system', Inzhenernoye obrazovaniye, No. 4, pp. 215216, (in Russian).

Noe, RA 2013, Human resource management: gaining a competitive advantage, New York, 758 p.

Petrov, V 2014, 'The word after the action', Rossiyskaya Gazeta, 22 April, (in Russian).

Safonov, AL 2012, 'Development and management of human potential in the public service of the Russian Federation', Chelovecheskiy capital, No. 9, p. 6, (in Russian). 